\title{
Comparison and correlation of ophthalmic and systemic manifestations with respect to CD4 counts in HIV infected adults
}

\author{
Dinesh R.B. ${ }^{1}$, Murthy K.R. ${ }^{2}$, Murthy K.R. ${ }^{3}$ \\ ${ }^{1}$ Dr. Dinesh R B., Consultant, Department of Vitreo Retina, Karnataka Institute of Endocrinology and Research \\ (Autonomous Institute of Dept of Medical Education, Govt. of Karnataka), SJICR campus, Jayanagar $9^{\text {th }}$ block \\ Bangalore, ${ }^{2}$ Dr. Krishna R Murthy, Consultant, Vitreo retina, Prabha Eye Clinic and Research Centre, Jayanagar $8^{\text {th }}$ \\ Block, Bangalore, ${ }^{3}$ Dr. K.R. Murthy, Consultant, Prabha Eye Clinic and Research Centre, Jayanagar $8^{\text {th }}$ block, \\ Bangalore, Karnataka, India.
}

Address for Correspondence: Dr. Dinesh R B., Consultant, Department of Vitreo Retina, Karnataka Institute of Endocrinology and Research (Autonomous Institute of Dept of Medical Education, Govt of Karnataka), SJICR Campus, Jayanagar $9^{\text {th }}$ block, Bangalore. Email: dinirb@gmail.com

\begin{abstract}
Purpose: To compare and correlate ophthalmic and systemic manifestations with respect to CD4 counts in HIV infected adults. Materials and Methods: In a prospective clinical study, 182 HIV positive patients were evaluated for their ophthalmic findings. All patients underwent complete ophthalmic examination including detailed history, best corrected visual acuity, slit lamp examination, indirect ophthalmoloscopy and +90D lens biomicroscopy. Fundus photographs were taken in patients with ocular manifestations. Routine blood tests including total and differential count, Hb levels, erythrocyte sedimentation rate, erythrocyte and platelet counts were done. Serologic tests (ELISA for IgM antibody) for toxoplasma, cytomegalovirus was done in clinically suspicious cases. VDRL, and chest x-ray was performed in cases suspected to have syphilis and tuberculosis respectively. Results: 182 patients were examined, $65.9 \%$ male and $34.1 \%$ being female patients. Most common systemic manifestation was pulmonary TB $(39.1 \%)$ ( $<<0.001)$, second common being oral candidiasis $(16.5 \%)(\mathrm{p}<0.001)$ followed by abdominal TB $(15.5 \%)$. Also, 37.9\% patients had ocular lesions out of which $15.4 \%$ had HIV retinopathy, second common was CMV retinitis $(9.3 \%)$ followed by HIV optic neuropathy (3.8\%). 34.1\% had CD4<100, 44\% between $01-100$ and $22 \%$ had CD4 $>200$. Twenty five $\%$ of patients with pulmonary TB had HIV retinopathy and $12 \%$ with pulmonary TB had CMV retinitis. Among the 30 oral candidiasis patients 8 (26.6\%) developed HIV retinopathy, where as 10\% developed CMV retinitis. Fifty seven \% of patients with HIV retinopathy had CD4<100, 28.6\% with CD4 between 101-200 and 14.3\% with CD4 >200. Similarly 47.1\% with CMV retinitis had CD4 <100, 52.9\% had CD4 101-200. None with CD4 >200 developed CMV retinitis. Conclusions: Study shows an increased prevalence of systemic diseases along with ocular diseases with decreased CD4 counts, particularly $<100$. Pulmonary TB is seen more frequently with $\mathrm{CD} 4<200$ and is also seen to be associated increasingly with ocular manifestations and more so when CD4 $<100$.
\end{abstract}

Key words: CD4 counts, Pulmonary TB, CMV retinitis, HIV retinopathy

\section{Introduction}

The Human Immunodeficiency Virus (HIV) infection has spread worldwide, with various adverse health and economic implications, particularly in the developing world with Sub Saharan Africa having highest prevalence.

Manuscript received: $14^{\text {th }}$ May 2017

Reviewed: $24^{\text {th }}$ May 2017

Author Corrected: $3^{\text {rd }}$ June 2017

Accepted for Publication: $10^{\text {th }}$ June 2017
The first report of the ocular manifestation of HIV/AIDS was noted by Holland et al in 1982 [1,2]. The first case in India was reported in 1995 by Jyotirmay Biswas [3].

HIV infection may involve the anterior or posterior segment of the eye. Anterior segment manifestations include keratitis, keratoconjunctivitis sicca and anterior 
uveitis. Orbital and adnexal findings include molluscum contagiosum and tumours of periocular tissues.

Posterior segment manifestations are more common than anterior segment.

Posterior segment involvement includes HIV retinopathy, and oppurtunistic infections like CMV retinitis, Toxoplasma retinitis, Pneumocystic carinii, Syphilitic retinitis, acute retinal necrosis, Progressive outer retinal necrosis, fungal retinitis and endophthalmitis.

Neuro ophthalmic manifestations are visual field defects, papilloedema, and optic neuritis.

The occurrence of ophthalmic complication associated with HIV infection group is significantly lower in the paediatric age group. Seventy five \% of adults with HIV/AIDS will experience ocular complications at some point of illness.

$\mathrm{CD}_{4+} \mathrm{T}$ lymphocyte count is a reliable predictor of ocular complications of HIV infection [4,5]. Highly active antiretroviral therapy (HAART), first introduced in 1995 by Dr. David Ho and co-workers, which has revolutionized the treatment of patients with AIDS and has decreased plasma levels of HIV RNA and increased $\mathrm{CD}_{4}+\mathrm{T}$ lymphocyte count, improving the immune function of patients with HIV infection $[6,7]$.

The clinical presentation of HIV related disease may be modified by HAART therapy, which has improved the prognosis of HIV infection.

There are reports of spontaneous resolution of CMV retinitis in patients with increased $\mathrm{CD}_{4}$ count related to such therapy, although the recovery in $\mathrm{T}$ lymphocyte may take many months [8].

\section{Methods}

Study Design: Prospective clinical study

Participants: 182 two HIV/AIDS positive patients were evaluated for their ophthalmic findings.

Data source: All patients underwent complete ophthalmic examination including detailed history, best corrected visual acuity, slit lamp examination, indirect ophthalmoloscopy and +90D lens biomicroscopy.
Additionally, fundus photographs were taken in patients with ocular manifestations.

Routine blood tests including total and differential count, hemoglobin levels, erythrocyte sedimentation rate, erythrocyte and platelet counts were done.

Serologic tests (ELISA for IgM antibody) for toxoplasma, cytomegalovirus was done in clinically suspicious cases. VDRL, and chest $\mathrm{x}$-ray was performed in cases suspected to have syphilis and tuberculosis respectively.

For all laboratory diagnosis of HIV, serum samples were considered positive only if they were found to be reactive by rapid screening enzyme immunoassay (TRIDOT test).

Diagnosis was confirmed by enzyme linked immunosorbant assay (ELISA).

A thorough medical examination was carried out by a physician to rule out any systemic disease.

Inclusion criteria: All patients aged above 18 yrs and confirmed to be HIV positive at Freedom Foundation hospital were included

Exclusion criteria: All patients less than 18 yrs old were not included in the study.

Statistical Methods: Descriptive statistical analysis has been carried out. Chi-square/Fisher Exact test has been used to find the significance of association of CD4 counts and systemic manifestations and Ocular manifestations.

\section{1) Significant figures}

+ Suggestive significance $0.05<\mathrm{P}<0.10$

* Moderately significant $0.01<\mathrm{P} \leq 0.05$

** Strongly significant $\mathrm{P} \leq 0.01$

2) Statistical software: The Statistical software namely SPSS 11.0, Stata 8.0, Systat 11.0, Medcalc and Effect Size calculator were used for the analysis of the data and Microsoft word and Excel have been used to generate graphs, tables etc. 


\section{Results}

Table-1: Age distribution patients studied.

\begin{tabular}{|c|c|c|}
\hline Age in years & Number & \% \\
\hline $20-30$ & 63 & 34.6 \\
\hline $31-40$ & 87 & 47.8 \\
\hline $41-50$ & 22 & 12.1 \\
\hline $51-60$ & 7 & 3.8 \\
\hline$>60$ & 3 & 1.6 \\
\hline Total & 182 & $35.12 \pm 8.60$ \\
\hline Mean \pm SD & \multicolumn{2}{|c|}{} \\
\hline
\end{tabular}

Among the 182 patients examined, 150 patients (82.4\%) were between $20-40$ age group with $47.8 \%$ being in $31-40$ age group with mean SD being $35.12+/-8.60$. Out of the total patients, 120 were male and 62 were female.

Table-2: Systemic manifestations of patients studied.

\begin{tabular}{|c|c|c|}
\hline Systemic manifestations & $\begin{array}{l}\text { Number } \\
(n=182)\end{array}$ & $\%$ \\
\hline Pulmonary TB & 71 & 39.1 \\
\hline Oral candidiasis & 30 & 16.5 \\
\hline Abdomen TB & 10 & 5.5 \\
\hline Diabetes Mellitus & 4 & 2.2 \\
\hline Cryptococcal meningitis & 3 & 1.6 \\
\hline Molluscum cantagiosum & 3 & 1.6 \\
\hline Hypertension & 2 & 1.1 \\
\hline Fatty liver & 2 & 1.1 \\
\hline Hbsag+ & 2 & 1.1 \\
\hline Renal calculi & 1 & 0.5 \\
\hline Diarrhoea & 1 & 0.5 \\
\hline Anaemia & 1 & 0.5 \\
\hline Ventricular Granulum & 1 & 0.5 \\
\hline Extranodal TB & 1 & 0.5 \\
\hline Ileo colitis & 1 & 0.5 \\
\hline Haemorroids & 1 & 0.5 \\
\hline Non hodgkin's lymphoma & 1 & 0.5 \\
\hline Skin lesions & 1 & 0.5 \\
\hline TB Lymphadenopathy & 1 & 0.5 \\
\hline Tuberculoma/ neurocysticerosis & 1 & 0.5 \\
\hline
\end{tabular}

The most common systemic manifestation was pulmonary TB (39.1\%), second common being oral candidiasis (16.5\%) followed by abdominal TB $(15.5 \%), \mathrm{DM}(2.2 \%)$ and cryptococcal meningitis and molluscum contagiosum being $(1.6 \%)$ each. 
Table-3: Ocular manifestations of patients studied.

\begin{tabular}{|c|c|c|}
\hline Ocular manifestations & $\begin{array}{c}\text { Number } \\
(\mathbf{n = 1 8 2})\end{array}$ \\
\hline HIV retinopathy & 28 & 15.4 \\
\hline CMV retinitis & 17 & 3.3 \\
\hline HIV Optic Neuropathy & 2 & 1.1 \\
\hline Phthisis bulbi & 2 & 1.1 \\
\hline Papilloedema & 2 & 1.1 \\
\hline Uveitis & 2 & 0.5 \\
\hline PED & 1 & 0.5 \\
\hline Frosted branch angitis & 1 & 0.5 \\
\hline Blepharitis & 1 & 0.5 \\
\hline Herpetic keratouveitis & 1 & 0.5 \\
\hline Optic atrophy & 1 & 0.5 \\
\hline Leukomia & 1 & 0.5 \\
\hline Ulcer & 1 & 0.5 \\
\hline Rhegmatogenous RD & 1 & \\
\hline HZO & 1 & \\
\hline
\end{tabular}

PED- Pigment epithelial detachment; HZO- Herpes zoster ophthalmicus; RD- Retinal detachment. In our study $37.9 \%$ patients had ocular lesions out of which $15.4 \%$ had HIV retinopathy, second common was CMV retinitis( $(9.3 \%)$ followed by HIV optic neuropathy(3.8\%). Papilloedema and anterior uveitis was seen in 2 patients each and rhegmatogenous RD and $\mathrm{HZO}$ was seen in 1 patient each

Table-4: Ocular manifestations of patients with systemic diseases

\begin{tabular}{|c|c|c|c|c|}
\hline \multirow{2}{*}{ Ocular manifestions } & \multicolumn{4}{|c|}{ Systemic diseases } \\
\cline { 2 - 5 } & $\begin{array}{c}\text { Pulm TB } \\
(\mathbf{n = 7 1 )}\end{array}$ & $\begin{array}{c}\text { Oral candidiasis } \\
(\mathbf{n = 3 0})\end{array}$ & $\begin{array}{c}\text { Abdomen TB } \\
(\mathbf{n = 1 0})\end{array}$ & $\begin{array}{c}\text { DM } \\
(\mathbf{n}=\mathbf{4})\end{array}$ \\
\hline HIV retinopathy & 18 & 8 & 1 & 1 \\
\hline CMV retinitis & 9 & 3 & - & - \\
\hline HIV Optic Neuropathy & 7 & 3 & - & - \\
\hline Phthisis bulbi & 1 & - & - & - \\
\hline Papilloedema & 1 & - & - & - \\
\hline Uveitis & - & - & - & - \\
\hline PED & - & - & - & - \\
\hline Frosted branch angitis & 1 & - & - & - \\
\hline Blepharitis & - & - & - & - \\
\hline Herpetic keratouveitis & - & - & - & - \\
\hline Optic atrophy & - & - & - & - \\
\hline Leukemia & 1 & - & - & - \\
\hline Ulcer & - & - & - & - \\
\hline Rhegmatogenous & 37 & - & & 3 \\
\hline HZO & & - & - & - \\
\hline Nil & - & - & - & - \\
\hline
\end{tabular}

PED- Pigment epithelial detachment; HZO- Herpes zoster ophthalmicus; RD- Retinal detachment 
Twenty five $\%$ of patients with pulmonary TB had HIV retinopathy and 12\% with pulmonary TB had CMV retinitis. Among the 30 oral candidiasis patients $8(26.6 \%)$ developed HIV retinopathy, where as $10 \%$ developed CMV retinitis.

Table-5: Association of systemic diseases with CD4 counts.

\begin{tabular}{|c|c|c|c|c|c|}
\hline \multirow{2}{*}{$\begin{array}{c}\text { Systemic } \\
\text { manifestation }\end{array}$} & \multicolumn{3}{|c|}{ CD4 counts } & \multirow{2}{*}{ Total } & P value \\
\cline { 2 - 5 } & $<\mathbf{1 0 0}$ & $\mathbf{1 0 1 - 2 0 0}$ & $\mathbf{> 2 0 0}$ & 71 & $<0.001 * *$ \\
\hline Pulmonary TB & $41(57.7 \%)$ & $23(32.4 \%)$ & $7(9.9 \%)$ & 30 & $<0.001 * *$ \\
\hline Oral candidiasis & $28(93.3 \%)$ & $2(6.6 \%)$ & 0 & 10 & 0.7677 \\
\hline Abdomen TB & 4 & 5 & 1 & 3 & 0.999 \\
\hline $\begin{array}{c}\text { Cryptococcal } \\
\text { meningitis }\end{array}$ & $(40.0 \%)$ & $(50.0 \%)$ & 1 & $(10.0 \%)$ & 3 \\
\hline $\begin{array}{c}\text { Molluscum } \\
\text { cantagiosum }\end{array}$ & $(33.3 \%)$ & $(33.3 \%)$ & 1 & 1 & $3.3 \%)$ \\
\hline
\end{tabular}

$57.7 \%$ of patients with pulmonary $\mathrm{Tb}$ had $\mathrm{CD} 4<100,32.4 \%$ had CD4 between $101-200$, where as only $9.9 \%$ had $\mathrm{CD} 4$ $>200$. Likewise $93.3 \%$ of oral candidiasis patients had CD4 >100 and 6.6\% was between 101-200 levels. None with CD4 $>200$ had oral candidiasis.

Table-6: Association of ocular manifestations with CD4 counts.

\begin{tabular}{|c|c|c|c|c|c|}
\hline \multirow{2}{*}{$\begin{array}{c}\text { Ocular } \\
\text { manifestation }\end{array}$} & \multicolumn{3}{|c|}{ CD4 counts } & \multirow{2}{*}{ Total } & \multirow{2}{*}{ P value } \\
\cline { 2 - 5 } & $\mathbf{< 1 0 0}$ & $\mathbf{1 0 1 - 2 0 0}$ & $\mathbf{> 2 0 0}$ & 28 & $0.0214 *$ \\
\hline HIV retinopathy & $16(57.1 \%)$ & $8(28.6 \%)$ & $4(14.3 \%)$ & 17 & $0.0301 *$ \\
\hline CMV retinitis & $8(47.1 \%)$ & $9(52.9 \%)$ & 0 & 7 & 0.9036 \\
\hline $\begin{array}{c}\text { HIV Optic } \\
\text { Neuropathy }\end{array}$ & $2(28.6 \%)$ & $4(57.1 \%)$ & $2(28.6 \%)$ & & 0 \\
\hline
\end{tabular}

This table correlates the ocular manifestations with CD4 counts with HIV retinopathy, CMV retinitis and HIV optic neuropathy

Table-7: CD4 counts and its association with Ocular manifestations.

\begin{tabular}{|c|c|c|c|c|c|c|}
\hline \multirow{2}{*}{$\begin{array}{c}\text { Ocular } \\
\text { Manifestations }\end{array}$} & \multicolumn{4}{|c|}{ CD 4 counts } & \multirow{2}{*}{ Total } & \multirow{2}{*}{$P$ value } \\
\hline & $<\mathbf{5 0}$ & 51-100 & $101-200$ & $>200$ & & \\
\hline HIV retinopathy & $\begin{array}{c}3 \\
(10.7 \%)\end{array}$ & $\begin{array}{c}13 \\
(46.4 \%)\end{array}$ & $\begin{array}{c}8 \\
(28.6 \%)\end{array}$ & $\begin{array}{c}4 \\
(14.3 \%)\end{array}$ & 28 & $0.049 *$ \\
\hline CMV retinitis & $\begin{array}{c}2 \\
(11.8 \%)\end{array}$ & $\begin{array}{c}6 \\
(35.3 \%)\end{array}$ & $\begin{array}{c}9 \\
(52.9 \%)\end{array}$ & - & 17 & 0.130 \\
\hline $\begin{array}{l}\text { HIV Optic } \\
\text { Neuropathy }\end{array}$ & $\begin{array}{c}1 \\
(14.3 \%)\end{array}$ & $\begin{array}{c}1 \\
(14.3 \%)\end{array}$ & $\begin{array}{c}3 \\
(42.9 \%)\end{array}$ & $\begin{array}{c}2 \\
(28.6 \%)\end{array}$ & 7 & 0.739 \\
\hline
\end{tabular}

Fifty seven \% of patients with HIV retinopathy had CD4<100, 28.6\% with CD4 between 101-200 and 14.3\% with CD4 $>200$. Similarly 47.1\% with CMV retinitis had CD4 <100, 52.9\% had CD4 101-200. None with CD4 >200 developed CMV retinitis. Also 28.6\% with HIV optic neuropathy had CD4 <100, 57.1\% had CD4 101-200 and 28.6\% had CD4 $>200$. 
Table-8: Association of Ocular manifestations with Systemic manifestations.

\begin{tabular}{|c|c|c|c|}
\hline \multirow{2}{*}{ Systemic manifestations } & \multicolumn{3}{|c|}{ Ocular manifestations when } \\
& \multicolumn{3}{|c|}{ CD4 <100 } \\
\cline { 2 - 4 } & HIV retinopathy & CMV retinitis & HIV Optic Neuropathy \\
\hline Pulmonary TB & 12 & 5 & 2 \\
\hline Oral candidias & 8 & 3 & 1 \\
\hline DM & 0 & 1 & 0 \\
\hline Abdomen TB & 0 & 9 & 3 \\
\hline Total & 20 & 0 & 0 \\
\hline
\end{tabular}

\section{Discussion}

HIV infection has become one of the world's greatest public health problems in recent years. Worldwide an estimated 37.2 million adults and 2.3 million children are infected with HIV as on 2006. Approximately 5.7 million people, of which 5.2 million are adults aged 1549 yrs were infected with HIV in India in 2005. The highest prevalence of HIV was found in Mumbai Karnataka corridor, Namakkal district of Tamilnadu and parts of Manipur and Nagaland. The first ophthalmic report of patient with ocular disease attributed to HIV in India was published in 1995 by Jyotirmay Biswas [3]. As $40-70 \%$ of AIDS patients develop ocular complications, role of ophthalmologist in management of HIV patients is becoming increasingly important [9].

In a series of 100 AIDS patients reported by Kumarasamy and co workers, the most common systemic manifestation was tuberculosis (TB) being $61.1 \%$, with most common form being pulmonary TB. This is due to high prevalence of systemic TB in India [10]. Biswas et al in their study which included 70 patients also found that pulmonary TB (50\%) was the most common systemic infection followed by oral candidiasis $(41.4 \%)$, P. carinii pneumonia (11.4\%) and HIV enteropathy (12.8\%) [11]. In our study out of a total of 182 patients, 100 patients had either single or multiple systemic infections where as 82 patients had no systemic infection. Most common systemic infection was TB with 83 patients $(45.6 \%)$. Pulmonary TB was the most common form seen in 71 patients $(39.1 \%)$ followed by abdominal TB with 10 patients (5.5\%) followed by extranodal TB and TB lymphadenopathy seen in 1 patient each. Oral candidiasis was seen in 30 patients $(16.5 \%)$ followed by DM in 4 patients $(2.2 \%)$. Cryptococcal meningitis and molluscum contagiosum was seen in 3 patients each. Non hodgkin's lymphoma and ventricular granuloma was seen in 1 patient each.
Beare et al in a study on all adult HIV patients admitted with fever to a large central hospital in Malawi, Africa found that $36 \%$ of patients had TB with pulmonary TB being the most common [12]. Biswas et al in another study of 100 patients had found that pulmonary TB $(67 \%)$ was the most common systemic manifestation followed by oral candidiasis (66\%) [13].

In our study we have tried to correlate the ocular and systemic manifestations. Out of 182 patients 69 patients (37.9\%) had ocular manifestations with $1.6 \%$ having multiple diseases where as 113 patients had no ocular findings. The most common ocular manifestation was HIV retinopathy seen in 28 patients $(15.4 \%)$ followed by CMV retinitis in 17 patients $(9.3 \%)$. Third most common was HIV optic neuropathy seen in 7 patients (3.8\%). Papilloedema and anterior uveitis was seen in 2 patients each. HZO and rhegmatogenous RD and optic atrophy were seen in 1 patient each. Biswas et al in their study found that $45.7 \%$ patients had ocular lesions with CMV (21.4\%) being the most common followed by HIV retinopathy $(12.8 \%)$. Anterior uveitis was seen in $4.2 \%$ where in our study it was $1.1 \%$ [11]. Biswas et al in another study of 100 patients had found that CMV retinitis seen in 17 patients $(17 \%)$ was the most common HIV associated ocular lesion followed by HIV retinopathy where as in our study CMV retinitis was the second most common ocular lesion with 9.3\% [13].

Irene Dejaco-Rushwurm et al in their study on ocular blood flow in $37 \mathrm{HIV}$ infected patients found that significant reduction in leukocyte density was seen in these patients and was the reason for HIV retinopathy [14]. Engstorm et al in a similar study concluded that miocrovasular changes were associated with increased zeta sedimentation (red cell aggregation) ratios and fibrinogen levels [15]. Biswas et al in their study found 
that 6 of 15 patients with HIV retinopathy had CD4+ counts $<200$ [13]. In our study 24 out of 28 patients had CD4 counts $<200$ with 16 having $<100$ CD4 counts showing a significant relation between CD4 count and HIV retinopathy $(\mathrm{P}=0.049)$. Sison et al in their study had found that less than $1.8 \%$ of HIV infected persons will develop CMV as their initial manifestation but in all 9\% patients had CMV infection [16]. Kuppermann et al tried to correlate CD4 counts with CMV and HIV retinopathy in HIV infected individuals [17]. The study found that 26 of 132 patients with AIDS had CMV retinitis. Subset analysis showed that $30 \%$ of patients with CD4 $<50$ had CMV and none above CD4 $>50$ had CMV retinitis. Similarly $45 \%$ of patients with CD4 $<50$ had HIV retinopathy while $16 \%$ patients with CD4 >50 had HIV retinopathy.

In our study all CMV patients had CD4 $<200$ with $52.9 \%$ having CD4 between 101-200. Among them $11.8 \%$ patients had CD4 $<50$ where as $35.3 \%$ had CD4 between 51-100. Very significantly none of the patients with CD4 $>200$ had CMV retinitis. Likewise $57.1 \%$ of patients with CD4 <100 had HIV retinopathy, 28.6\% had CD4 between 101-200 and 14.3\% with CD4 >200, thus strongly suggesting the likelihood of HIV retinopathy with decreased CD4 counts. To add to it even HIV optic neuropathy patients $(71.4 \%)$ had CD4 $<200$. Four of our patients with CMV retinitis progressed to have rhegmatogenous RD. A variant of CMV retinitis, frosted branch angitis was seen in 1 patient. Biswas et al in their study found that $30 \%$ of patients with pulmonary $\mathrm{TB}$ and $25.7 \%$ with oral candidiasis developed ocular lesions [11].

In our study $54.7 \%$ of patients with pulmonary TB developed ocular lesions where as $45.3 \%$ patients did not develop any ocular lesions. Likewise $46.7 \%$ with oral candidiasis had ocular lesions where as $53.3 \%$ did not develop any ocular lesion. Three patients (40\%) with abdominal TB developed ocular lesions. Most of the studies have tried to correlate the systemic and ocular disease only. In our study we have tried to do the same but added a new element of comparing with CD4 levels.

In our study it was seen that pulmonary TB was most common $(37.7 \%)$ with CD4 $<100(\mathrm{P}<0.001)$ and $93.3 \%$ of oral candidiasis affected patients had CD4 $<100(\mathrm{P}<0.001)$ thereby clearly showing significant relation with decreased CD4 counts. None of the patients with CD4 >200 developed oral candidiasis.
Beare et al found in their study that CD4 counts was $<100$ in $25 \%$ of hospitalized AIDS patients in Africa. Significantly none of the patients developed CMV retinitis in their study [12]. In our study we have tried to correlate systemic and ocular lesions with decreased CD4 counts and found that $60 \%$ of patients with HIV retinopathy with $\mathrm{CD} 4<100$ developed pulmonary $\mathrm{TB}$ and $40 \%$ developed oral candidiasis which was very significant. Fifty five\% of patients with CMV retinitis with CD4 counts less than 100 developed pulmonary TB and 3 patients (33\%) developed oral candidiasis. This study clearly indicates the increased association of systemic infections and ocular infections when CD4 counts are decreased particularly CD $4<100$.

However there are a few observations such as shown in Beare et al where in none of the patients developed CMV retinitis in spite of CD4 below 100 and associated with pulmonary $\mathrm{TB}$, which was in line with other surveys on AIDS in Africa [12]. The reason for rarity of CMV retinitis in Africa is generally considered to be due to mortality of people with AIDS early in the disease progression and before or shortly after the onset of profound immunosuppression. CD4 counts have been found to be below 100 cells $/ \mathrm{mm}^{3}$ in as many as $25 \%$ of hospitalized AIDS patients in Africa but accelerated disease progression may mean that their life expectancy is short and hence CMV retinitis is rarely seen.

Studies of ocular involvement in developing countries of Sub Saharan Africa and South Asia have been of considerable interest due to different sexual behavior (less homosexuality), different systemic manifestations like TB, poor hygiene, poor availability of health care facilities and poor awareness of early signs and symptoms of HIV infection. Kaposi's sarcoma was not at all reported in our study. It was not reported in a series of 100 patients by Biswas et al. Only two cases of Kaposi's sarcoma, one in a 19 yr old male AIDS patient from Madras and another $35 \mathrm{yr}$ old female from Bombay were reported in 1996 and 1993 respectively. A careful observation and comparison of studies done on HIV patients in Western countries, Asia and African countries showed differences in some important aspects such as sexual habits, microbiologic environment and lifestyles.

\section{Conclusions}

We conclude that HIV is becoming an epidemic in our population and is affecting the reproductive age group 
with males being most commonly affected, the commonest route being sexual route. All HIV patients should undergo detailed ophthalmic evaluation as many patients are not aware of the affection of the eye as patients are asymptomatic. It is important to correlate between ocular and systemic manifestations and CD4 counts. As has been seen in this study, there is an increased prevalence of systemic diseases along with ocular diseases with decreased CD4 counts, particularly $<100$. In particular, CMV retinitis has been time and again shown to be seen significantly in patients with CD4 $<200$ and more so in patients with CD4 $<100$. Pulmonary TB is seen more frequently with CD $4<200$ and is also seen to be associated increasingly with ocular manifestations and more so when CD $4<200$. The nature of systemic manifestations and ocular manifestations seem to be different from region to region but overall the risk of developing them is seen with decreased CD4 counts. HIV is spreading worldwide and affecting reproductive age group who are the backbone of any country. So society must be educated about HIV/AIDS. Ophthalmologists need to be aware and recognize ocular lesions in HIV infected as it may help in early diagnosis and prompt management of disease.

\section{Funding: Nil, Conflict of interest: None Permission of IRB: Yes}

\section{References}

1. Sarraf D, Ernest JT.AIDS and the Eyes. The Lancet 1996; 348(9026):525-28. DOI: http://dx.doi.org/ 10. 1016/ S0140-6736(05)65389-5

2. Holland G.N, Gottlieb M.S, Yee RD et al. Ocular disorders associated with a new severe acquired cellular Immunodeficiency Syndrome. Am J Ophthalmol 1982; 93(4): 393 - 402.

3. Biswas J, Madhavan HN, Badrinath SS. Ocular lesions in AIDS: a report of first two cases in India. Indian J Ophthalmol. 1995 Jun;43(2):69-72.

4. Cunningham ET Jr, Margolis TP. Ocular manifestations of HIV infection. N Engl J Med. 1998 Jul 23; 339(4):236-44.

5. Turner B J, Hect FM, Ismail RB. CD4+ T Lymphocyte measures in the treatment of individuals infected with Human Immunodeficiency Virus type 1: A review for clinical practitioners. Arch Intern Med
1994(14); 154:1561-73. doi:10.1001/archinte. 1994. 00420140022004 .

6. Collier AC, Coombs RW, Schoenfeld DA, Bassett RL, Timpone J, Baruch A, Jones M, Facey K, Whitacre C, McAuliffe VJ, Friedman HM, Merigan TC, Reichman RC, Hooper C, Corey L. Treatment of human immunodeficiency virus infection with saquinavir, zidovudine, and zalcitabine. AIDS Clinical Trials Group. N Engl J Med. 1996 Apr 18;334(16):1011-7.

7. Hammer SM, Squires KE, Hughes MD, Grimes JM, Demeter LM, Currier JS, Eron JJ Jr, Feinberg JE, Balfour HH Jr, Deyton LR, Chodakewitz JA, Fischl MA. A controlled trial of two nucleoside analogues plus indinavir in persons with human immunodeficiency virus infection and CD4 cell counts of 200 per cubic millimeter or less. AIDS Clinical Trials Group 320 Study Team. N Engl J Med. 1997 Sep 11;337(11): 725-33.

8. J.Brian Reed, M.D, Ivan R, Schwab, MD, et al. Regression of Cytomegalovirus retinitis associated with Protease-inhibitor treatment in patients with AIDS. Am J Ophthalmology 1997; 124(2):199-205. https://doi.org /10. 1016/ S0002-9394(14)70784-6

9. Rao NA. Acquired Immunodeficiency Syndrome and its ocular complications. Indian J Ophthalmology 1994; 42(2): 51-63.

10. Kumarasamy N, Solomon S, Jayaker Paul SA, Venilla R, Amalraj RE. Spectrum of opportunistic infections among AIDS patients in Tamil Nadu, India. Int J STD AIDS. 1995 Nov-Dec;6(6):447-9.

11. Biswas JB, Joseph A, Raizada S, Kumarsamy. N, Solomon S. Ophthalmic manifestations of Human Immunodeficiency Virus (HIV) infection in India. Indian J. Ophthalmol 1999; 47(2):87-93.

12. Beare NA, Kublin JG, Lewis DK, Schijffelen MJ, Peters RP, Joaki G, Kumwenda J, Zijlstra EE. Ocular disease in patients with tuberculosis and HIV presenting with fever in Africa. Br J Ophthalmol. 2002 Oct;86 (10):1076-9.

13. Biswas J, Madhavan HN, George A E, et al. Ocular lesions associated with HIV infection in India: A series of 100 consecutive patients evaluated at a referral centre. Am J ophthalmol 2000;129(1): 9-15. 
14. Rushwurm ID, Kiss B, Rainer G, et al. Ocular blood flow in patients infected with Human Immunodeficiency Virus. Am J Ophthalmol 2001; 132 (5): 720-26. https://doi.org/10.1016/S0002-9394(01) 01095-9.

15. Engstrom RE Jr, Holland GN, Hardy WD, Meiselman HJ. Hemorrhologic abnormalities in patients with Human Immuno Deficiency Virus and ophthalmic Microvasculopathy. Am J Ophthalmol 1990;109(2): 153-61.
16. Rebecca F Sison, Gary N Holland et al. Cytomegalovirus retinopathy as the initial manifestation of the acquired immunodeficiency syndrome. American J Ophthalmology 1991;112(3): 243-249. DOI: http://dx. doi. org/10.1016/S0002-9394(14)76724-8.

17. Kuppermann B D, John G Petty et al. Correlation between $\mathrm{CD} 4+$ counts and prevalence of cytomegalovirus retinitis and human immunodeficiency virus-related noninfectious retinal vasculopathy in patients with acquired immunodeficiency syndrome. American J Ophthalmology May 1993;115(5): 575-582.

\section{How to cite this article?}

Dinesh R.B, Murthy K.R, Murthy K.R. Comparison and correlation of ophthalmic and systemic manifestations with respect to CD4 counts in HIV infected adults. Int J Med Res Rev 2017;5(06):538-546. doi:10.17511/ijmrr. 2017.i06.01. 